\title{
Bilateral Temporal Lobe MRI Changes in Uncomplicated Hypoglycemic Coma
}

\author{
B.F. Boeve, D.G. Bell and J.H. Noseworthy
}

\begin{abstract}
We report bilateral temporal lobe MRI findings in a patient following an episode of prolonged hypoglycemia uncomplicated by coexisting anoxia, hypotension, acidosis, drug intoxication, infection, or status epilepticus. The MRI findings are discussed in relation to the experimental and human data on hypoglycemic neuronal injury.
\end{abstract}

\begin{abstract}
RÉSUMÉ: Anomalies bilatérales du lobe temporal au RMN dans un cas de coma hypoglycémique simple. Nous rapportons des anomalies bilatérales du lobe temporal à la RMN chez un patient, suite à un épisode d'hypoglycémie prolongée non compliquée par une anoxie, une hypotension, une acidose, un intoxication médicamenteuse, une infection ou un état de mal épileptique coexistant. Nous discutons de ces observations en relation avec les données expérimentales et humaines sur les lésions neuronales hypoglycémiques.
\end{abstract}

Can. J. Neurol. Sci. 1995; 22: 56-58

Hypoglycemic coma is a serious complication of poorly controlled diabetes. Unilateral temporal lobe MRI changes were previously described in a single patient with irreversible amnesia following profound hypoglycemia. ' We report bilateral temporal lobe MRI changes and subsequent severe anterograde amnesia and seizures in a diabetic man following an episode of prolonged isolated hypoglycemia.

\section{Case Report}

A 42-year-old male with a 12-year history of insulin-dependent diabetes mellitus was found unresponsive in his apartment 30 hours after leaving a casino. He had experienced four prior episodes of hypoglycemic coma, each of which had quickly responded to intravenous glucose without obvious clinical sequelae. Paramedics at the scene reported him to be comatose with a blood pressure of $116 / 48 \mathrm{~mm} \mathrm{Hg}$ and pulse of 91 (respiratory rate was not noted). They administered $50 \mathrm{ml}$ of $50 \%$ dextrose without obtaining a blood glucose level first. He did not improve. One hour later at a local hospital he remained comatose (Glasgow Coma Score of 3), and his blood pressure was $124 / 74 \mathrm{~mm}$ $\mathrm{Hg}$, pulse was 84 , and respiratory rate was 44 . Blood glucose was 77 $\mathrm{mg} / \mathrm{dl}$. Electrolytes, complete blood count, and arterial blood gases were normal. He was intubated, maintained on intravenous dextrose, and transferred to the Mayo Clinic.

On arrival four hours later his vitals signs were stable. He had no eye opening or response to verbal stimuli. He had roving conjugate eye movements, the pupils were $3 \mathrm{~mm}$ and reactive, the corneal and vestibuloocular reflexes were intact, and there was no meningismus. He flexed his arms and withdrew his legs to pain, and the plantar responses were extensor. Investigations revealed a serum glucose of $259 \mathrm{mg} / \mathrm{dl}$ and a white blood count of $17,000 \times 10^{6} / \mathrm{L}$. Arterial blood gases on an $\mathrm{FIO}_{2}$ of $100 \%$ were $\mathrm{paO}_{2} 337 \mathrm{~mm} \mathrm{Hg}, \mathrm{paCO}_{2} 35 \mathrm{~mm} \mathrm{Hg}, \mathrm{pH} 7.46, \mathrm{HCO}_{3} 26$ $\mathrm{mmol} / \mathrm{L}$. Serum and urine drug screens were negative. Cerebrospinal fluid analysis, serologies, and cultures were normal except for a glucose of $126 \mathrm{mg} / \mathrm{dl}$. Complete CSF analysis four days later again showed only an elevated glucose level. Noncontrast CT on admission was normal. EEG on three occasions showed only generalized slow activity. MRI three days after admission demonstrated increased signal intensity throughout the hippocampal formations bilaterally with additional scattered areas of increased signal intensity in the temporal and occipital gray matter bilaterally (Figures A and B). There was no abnormal gadolinium enhancement, and T1-weighted images were normal.

Two days later he was extubated. He opened his eyes to verbal stimuli but did not follow simple commands. He never engaged in eye contact with family members and remained mute. He showed no further improvement during the next five days and was transferred to another hospital to be closer to family.

Approximately four weeks after his insult, his speech returned and he was later able to ambulate without assistance. He was eventually transferred to a structured living facility with 24-hour nursing care where he has remained for over six months, independent in self-cares but requiring daily reorientation and assistance with insulin and antiepileptic drug administration. He is oriented to person and place only, is intermittently verbally aggressive, and has marked deficits in learning and memory, insight, and judgment. He has averaged two generalized tonicclonic seizures per month beginning approximately three months after his insult. These have continued despite repeated adjustments of his antiepileptic medications. The patient and his family have refused further psychometric, radiologic, and electroencephalographic testing.

\section{Discussion}

Hypoglycemia, ischemia, and status epilepticus result in selective neuronal necrosis. ${ }^{2.3}$ Structural changes in neuronal dendrites may be followed by perikaryal cytoclasis with relative sparing of axons and the non-neuronal neuropil. It has been postulated that binding of excitotoxic amino acids to receptors

From the Departments of Neurology (B.F.B., J.H.N.) and Radiology (D.G.B.), Mayo Clinic/Mayo Foundation, Rochester, Minnesota

RECEIVED DECEMBER 14, 1993. ACCEPTED IN FINAL FORM JULY 28, 1994 Reprint requests to: Dr. John H. Noseworthy, Department of Neurology, Mayo Clinic, 2001 st Street SW, Rochester, Minnesota 55905 USA 


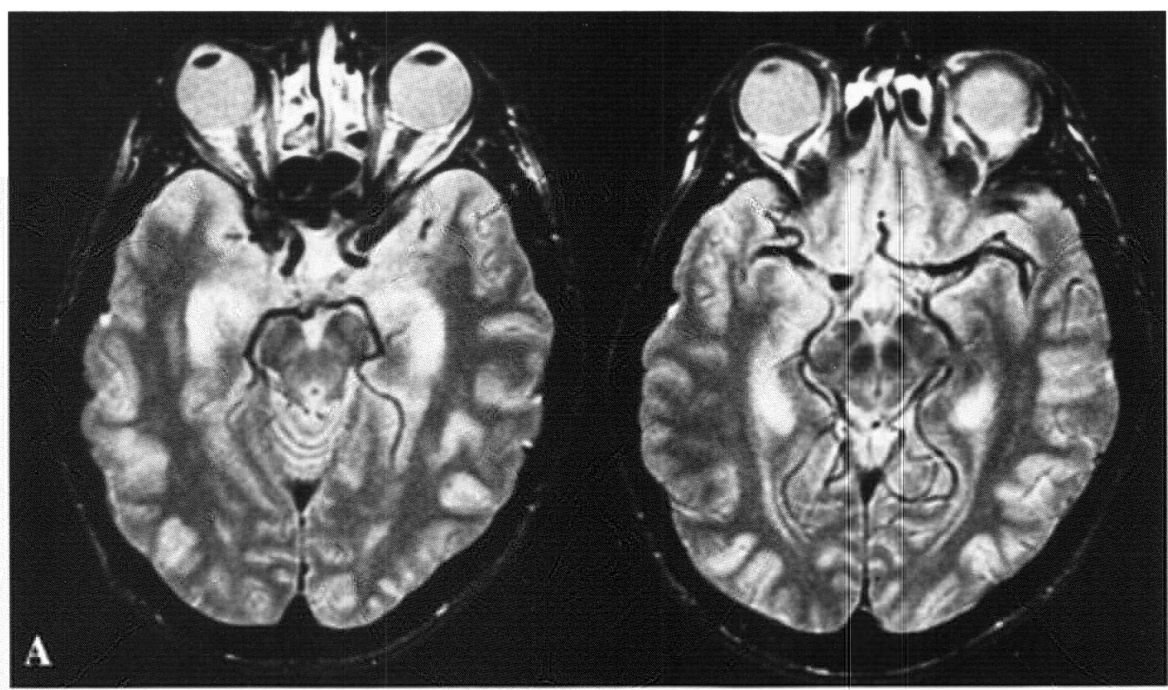

Figure (A): Axial proton-density $[T R=2500 \mathrm{msec}, T E=40 \mathrm{msec}]$.

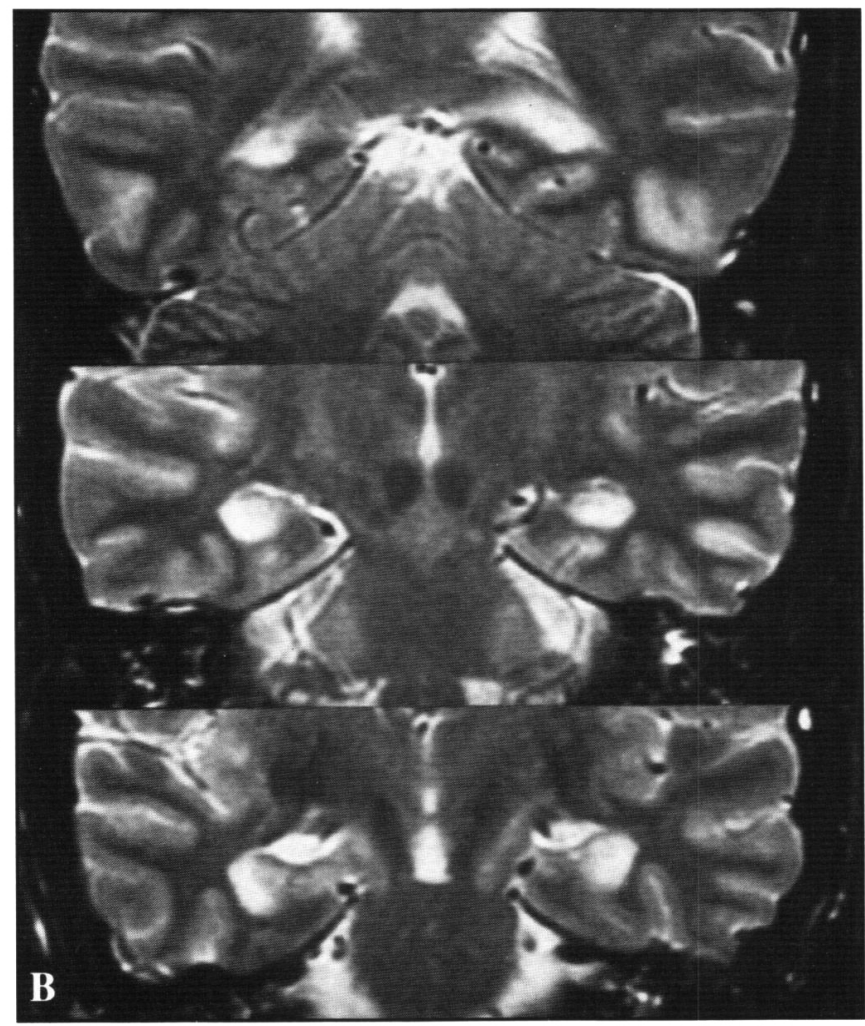

Figure $(B):$ Coronal T2-weighted $[T R=2300 \mathrm{msec}, T E=80 \mathrm{msec}]$ $M R I(1.5 T)$ demonstrates increased signal intensity throughout the hippocampal formations bilaterally. Scattered areas of increased signal are also present within the peripheral cortex of the temporal and occipital lobes bilaterally.

on neuronal dendrites in this setting may result in selective neuronal death, sparing axons and glia. ${ }^{4-6}$ If there is coexisting severe lactic acidosis, there is more widespread damage to the non-neuronal neuropil with pannecrosis. ${ }^{7}$ Experimental studies demonstrate topographical differences in the patterns of structural damage with these different disorders (selective vulnerability). ${ }^{2}$ Neurons in the superficial cerebral cortex and dorsolateral caudate are damaged in profound hypoglycemia. In the hippocampus, necrosis is common in the dentate gyrus and may extend into the medial subiculum, CAl pyramidal cells and dentate granule cells. Pannecrosis (infarction) does not occur in pure hypoglycemia, presumably because lactic acid cannot be produced. Cerebellar Purkinje cells, and thalamic and brainstem neurons are less prone to injury in hypoglycemia than in ischemia, although Purkinje cell damage may occur in severe cases. ${ }^{5}$ With cerebral ischemia, however, neurons in the middle laminae of the cerebral cortex (layer 1 spared), dorsolateral caudate, reticular thalamic nuclei, cerebellar Purkinje cells, and hippocampal CA4 and CAl pyramidal neurons are selectively vulnerable, with sparing of the dentate gyrus. The pattern of injury differs slightly in status epilepticus. Purkinje cells are less vulnerable and necrosis is seen in laminae 3 and 4 of the cerebral cortex. Experimental evidence suggests there may also be involvement of neurons in the pars reticulata and globus pallidus. Caudate and thalamic neurons may be less prone to injury.

Recent experimental studies have further characterized hypoglycemia-induced hippocampal injury. Selective CAl and dentate gyrus damage was reproduced in glucose-free organotypic hippocampal cultures to which aspartate (but not glutamate) had been added. ${ }^{8}$ The authors propose that this regional vulnerability may be mediated by an early TTX-sensitive component and a more extended NMDA receptor activation. Glucocorticoids exacerbate hypoglycemic and hypoxic hippocampal injury, possibly by impairing astrocyte function. ${ }^{9}$ Hypoglycemia also activates potassium channels in hippocampal neurons, and the cellular location of these channels may differ among the various hippocampal cell types. ${ }^{10}$ The selective vulnerability of the hippocampus with relative cerebellar sparing in hypoglycemia may be due in part to regional differences in brain glucose influx, as shown experimentally by LaManna and Harik. ${ }^{11}$

The few published human neuropathologic reports also describe CA1 and dentate gyrus damage following hypoglycemia, although the degree and pattern of injury among these cases are not as uniform as noted in animal models. ${ }^{4,12}$ Auer et al. noted dentate granule cell necrosis in one of three patients studied neuropathologically after profound hypoglycemia. ${ }^{4} \mathrm{Ng}$ 
et al. compared the neuropathologic findings in cardiac arrest, hypoglycemia, and status epilepticus. ${ }^{12}$ Neuronal damage in the dentate fascia was observed in several cases of each group, although the lateral limb was involved more frequently in hypoglycemia than the other two groups.

The only published report of an abnormal MRI in a patient following hypoglycemic coma showed radiologic and psychometric evidence of left hippocampal damage, ${ }^{1}$ whereas our patient has peripheral cortex and bilateral hippocampal lesions. Perhaps an MRI obtained with a stronger magnetic field (Chalmers et al. used a $0.08 \mathrm{~T}$ scanner) would have detected a subtle right hippocampal abnormality, as well. Alternatively, the marked MRI abnormalities in our patient may signify more severe hypoglycemic damage, which correlates with his more severe neurologic impairment. Bilateral hippocampal MRI abnormalities similar to those seen in our patient have also been described in complex partial status epilepticus ${ }^{13}$ and limbic encephalitis. ${ }^{14.15}$

We believe the signal abnormalities in our patient represent increased cellular water content secondary to early necrosis rather than simply edema. We would expect to find bilateral hippocampal atrophy, as well as patchy cortical encephalomalacia, in a subsequent MRI. Although we were unsuccessful in obtaining another MRI to confirm this, his persistent neurologic deficits are quite consistent with bilateral hippocampal damage.

In summary, our patient suffered a severe and presumably prolonged hypoglycemic episode, as confirmed by his subnormal serum glucose following intravenous glucose. There was no clinical or laboratory evidence of coexisting anoxia, hypotension, acidosis, drug intoxication, infection, or status epilepticus, although it remains possible that he was hypotensive or hypoxic before he received medical attention. We speculate that his persistent amnesia, seizures, and MRI findings, reflect necrosis of selectively vulnerable neurons in the superficial cerebral cortex and hippocampus (combined $\mathrm{CA} 1$ and dentate gyrus) as described in the neuropathological and experimental literature. ${ }^{2-4,12}$ We are unaware of a previous description of bilateral temporal lobe MRI changes from uncomplicated hypoglycemia.

\section{REFERENCES}

1. Chalmers J, Risk MTA, Kean DM, et al. Severe amnesia after hypoglycemia: clinical, psychometric, and magnetic resonance imaging correlations. Diabetes Care 1991;14: 922-925.

2. Auer RN, Siesjo BK. Biological differences between ischemia, hypoglycemia, and epilepsy. Ann Neurol 1988; 24: 699-707.

3. Auer RN, Wieloch T, Olsson Y, Siesjo BK. The distribution of hypoglycemic brain damage. Acta Neuropathol 1984; 64: 177-191.

4. Auer RN, Hugh J, Cosgrove E, Curry B. Neuropathologic findings in three cases of profound hypoglycemia. Clin Neuropathol 1989; 8: 63-68.

5. Auer R, Kalimo H, Olsson $\mathrm{Y}$, Wieloch $\mathrm{T}$. The dentate gyrus in hypoglycemia: pathology implicating excitotoxin-mediated neuronal necrosis. Acta Neuropathol 1985; 67: 279-288.

6. Olney JW. Glutamate-induced retinal degeneration in neonatal mice. Electron microscopy of the acutely evolving lesions. J Neuropathol Exp Neurol 1969; 28: 455-474.

7. Myers RE. Lactic acid accumulation as a cause of brain edema and cerebral necrosis resulting from oxygen deprivation. In: Korobkin R, Guillemineault G, eds. Advances in Perinatal Neurology. New York: Spectrum Publishers, 1979: 85-114.

8. Tasker RC, Coyle JT, Vornov JJ. The regional vulnerability to hypoglycemia-induced neurotoxicity in organotypic hippocampal culture: protection by early tetrodotoxin or delayed MK-801. J Neurosci 1992; 12: 4298-4308.

9. Tombaugh GC, Yang SH, Swanson RA, Sapolsky RM. Glucocorticoids exacerbate hypoxic and hypoglycemic hippocampal injury in vitro: biochemical correlates and a role for astrocytes. J Neurochem 1992; 59: 137-146.

10. Tromba C, Salvaggio A, Racagni G, Volterra A. Hypoglycemiaactivated $\mathrm{K}$ channels in hippocampal neurons. Neurosci Lett 1992; 143: 185-189.

11. LaManna JC, Harik SI. Regional comparisons of brain glucose influx. Brain Res 1985; 326: 299-305.

12. $\mathrm{Ng} \mathrm{T}$, Graham DI, Adams JH, Ford I. Changes in the hippocampus and the cerebellum resulting from hypoxic insults: frequency and distribution. Acta Neuropathol 1989; 78: 438-443.

13. Lee BI, Lee BC, Hwang YM, et al. Prolonged ictal amnesia with transient focal abnormalities on magnetic resonance imaging. Epilepsia 1992; 33: 1042-1046.

14. Kodama T, Numaguchi $Y$, Gellad FE, et al. Magnetic resonance imaging of limbic encephalitis. Neuroradiology 1991; 33: 520-523.

15. Lacomis D, Khoshbin S, Schick RM. MR imaging of paraneoplastic limbic encephalitis. J Comput Assist Tomogr 1990; 14: 115-117. 